\title{
Numerical Modeling on Dynamic Characteristics of Jointed Rock Masses Subjected to Repetitive Impact Loading
}

\author{
Jie Liu $\mathbb{D}^{1,2}$ Yan-Bin Song $\mathbb{D}^{1},{ }^{1}$ and Yue-Mao Zhao $\mathbb{D}^{3}$ \\ ${ }^{1}$ Key Laboratory of Rock Mechanics and Geohazards of Zhejiang Province, Shaoxing University, Shaoxing 312000, China \\ ${ }^{2}$ Zhejiang Collaborative Innovation Center for Prevention and Control of Mountain Geological Hazards, Shaoxing 312000, China \\ ${ }^{3}$ College of Energy and Mining Engineering, Shandong University of Science and Technology, Qingdao 266590, China
}

Correspondence should be addressed to Yue-Mao Zhao; zhaoyuemao@sdust.edu.cn

Received 12 November 2021; Accepted 6 December 2021; Published 21 December 2021

Academic Editor: Xiao Wang

Copyright (C) 2021 Jie Liu et al. This is an open access article distributed under the Creative Commons Attribution License, which permits unrestricted use, distribution, and reproduction in any medium, provided the original work is properly cited.

\begin{abstract}
A discrete element method code was used to investigate the damage characteristics of jointed rock masses under repetitive impact loading. The Flat-Joint Contact Model (FJCM) in the two-dimensional particle flow code (PFC2D) was used to calibrate the microparameters that control the macroscopic behavior of the rock. The relationship between macro- and microparameters by a series of uniaxial direct tension and compression numerical tests based on an orthogonal experimental design method was obtained to calibrate the microparameters accurately. Then, the Synthetic Rock Mass (SRM) method that incorporates joints into the calibrated particle model was used to construct large-scale jointed rock mass specimens, and the repetitive drop hammer impact numerical tests on SRM specimens with different numbers of horizontal joints and dip angle joints were carried out to study the damage evolution, stress wave propagation, and energy dissipation characteristics. The results show that the greater the number of joints, the greater the number of cracks generated, the greater the degree of damage, and the more energy dissipated for rock masses with horizontal joints. The greater the dip angle of joints, the less the number of cracks generated, the less the degree of damage, and the less energy dissipated for rock masses with different dip angles of joints. The impact-induced stress waves will be reflected when they encounter preexisting joints in the process of propagation. When the reflected stress waves meet with subsequent stress waves, the stress waves will change from compressional waves to tensile waves, producing tensile damage inside rock masses.
\end{abstract}

\section{Introduction}

Joints are commonly found in rock masses and play a key role in controlling the mechanical behavior of the rock structure, not only slowing down and attenuating the propagation of stress waves but also accelerating the damage of jointed rock masses and dominating the failure modes, which has a significant impact on the dynamic mechanical properties of rock masses $[1,2]$. Engineering rock masses are often subjected to repetitive impact loads, such as multiple strikes of artillery shells on targets, multiple blasting, and mechanical disturbances [3]. Especially in underground metal mining, the failure of surrounding rock subjected to repeated impact loading often occurs due to continuous blasting operations [4]. The damage of rock masses under repetitive impact loading is a dynamic process of cumulative damage evolution. Therefore, it is important to study the damage evolution of rock masses under repetitive impact loading to understand the dynamic characteristics of rock masses and thus assess the structural stability of rock engineering.

At present, the study of the dynamic mechanical properties of rock masses is widely carried out using split Hopkinson pressure bars (SHPB) by laboratory experiments. $\mathrm{Li}$ et al. [5] conducted repetitive impact tests on granite using a $75 \mathrm{~mm}$ diameter SHPB. They concluded that the rock damage generated by each impact is low when the peak impact stress is less than between $60 \%$ and $70 \%$ of the static uniaxial strength of the rock. Li et al. [6] used a SHPB device driven by a pendulum hammer to repetitively impact green 
sandstone and revealed the intrinsic mechanism of damage evolution of sandstone from the perspectives of acoustic properties, energy dissipation, deformation characteristics, and microfracture evolution. Wang et al. [7] investigated the damage evolution mechanism of black mica granite by cyclic impact with four different stress amplitudes and discussed the damage stress threshold of impacted rocks in conjunction with the crack initiation stress. Dai et al. [8] analyzed the dynamic properties, damage characteristics, energy dissipation, and damage pattern of rock specimens containing holes under cyclic impact loading. The above studies are rock property tests, and the degree of influence on the fractures is not considered. Other researchers reported the influence of the jointed structure on the dynamic mechanical properties of rocks. Zheng et al. [9] studied the fragmentation distribution pattern of bedding sandstone under freeze-thaw cycles using SHPB but cannot analyze in depth the relationship between crack extension and bedding dip angle under dynamic loading. Xu et al. [10] analyzed the effect of bedding angle on crack extension under dynamic loading and found that dynamic cracks are prone to deflection after encountering bedding. Qiu et al. [11] focused on the influence of layer plane structure on dynamic tensile properties and fracturing behavior of this phyllite and found that the damage of bedding rock masses with different layer dip angles shows three different damage patterns. Zou et al. [12] studied the mechanical properties and crack extension behavior of single-flawed gypsum specimens under dynamic and quasistatic strain rate conditions and found that the main cracks could be divided into two types: shear cracks and tensile cracks. Zhou et al. [13] investigated the dynamic fracture behavior of mixed type I and type I/II cracks in tunnels under impact loading, showing that for type I cracks, the cracks propagate in the direction of the precrack, while mixed type I/II cracks propagate at an early stage at an angle to form wing-shaped cracks and finally propagate in the direction of the principal stress.

All of the above laboratory experimental studies were carried out using SHPB devices. As SHPB impact tests are affected by transient damage and environmental disturbances, many damage measurement techniques, such as acoustic emission measurements, acoustic wave measurements, and CT scans, are difficult to be used for real-time damage measurements in rock impact tests. In addition, the research objects are mainly rock blocks or small-scale rock mass specimens, which cannot reflect the dynamic impact damage characteristics of large-scale jointed rock masses. Compared with laboratory tests, numerical simulation can consider more factors and has significant advantages in terms of time, cost, and complexity. The discrete element method (DEM) based on discontinuous media is a direct modeling approach of impact-induced damage. It has been widely and successfully applied in modeling the dynamic behavior of rocks. Numerical codes based on DEM include UDEC, 3DEC, PFC2D, and PFC3D. This method uses contact relations between discrete units instead of complex intrinsic relationships and can effectively simulate the macroscopic mechanical behavior of block or granular structural materials. In this paper, a distinct element code
PFC2D was used to study the damage evolution, stress wave propagation, and energy dissipation characteristics of jointed rock mass specimens with different numbers and dip angle joints under repetitive drop hammer impact loading.

\section{Microparameters Calibration of FJCM}

2.1. FJCM. The particle flow program PFC2D is a power tool for the simulation of the macroscopic mechanical properties of rock materials by discretizing the rock into rigid and finite-sized particles and describing the interaction between particles by defining particle contact constitutive relationship [14]. Potyondy and Cundall [15] developed the Parallel Bond Model (PBM). In this model, circular or spherical particles are bonded at their contact points using contact or parallel bonds to behave like a brittle material. Nevertheless, the high tensile strength of the rock obtained from PBM leads to a compression-tension strength ratio (UCS/TS) of 34 , whereas the UCS/TS of real rock is usually greater than 10 , and the simulation results cannot match the real rock [16]. To overcome the limitation in PBM, Potyondy [17] proposed FJCM that can fully reflect the rock properties, as shown in Figure 1. FJCM consists of rigid balls joined by flat-joint contacts, which can simulate the behavior of an interface between two notional surfaces. The effective surface of each grain is defined by the notional surface. Thus, the grain can be considered a skirted particle. This fictitious notional surface can increase UCS/TS by grain interlocking, which reflects rock behavior more realistically at the microscale. Additionally, the interface is a flat line and discretized into several elements. Each element can be bonded or unbonded, and the breakage of each bonded element contributes partial damage to the interface. Because the interface consists of a few elements in FJCM, it can be partially damaged. The interface in FCJM still exists and resists rotation even after breakage. Therefore, this model can significantly increase the UCS/TS of the rock, which is a better match to the real rock than PBM. In this paper, the intact rock is established with FJCM; the main microparameters include the number of elements in each bond $N$, residual friction coefficient of bond $\mu$, tensile strength of contact $\sigma_{c}$, cohesion of bond $c$, friction angle of bond $\varphi$, effective modulus of bond $E_{c}$, stiffness ratio of contact $k_{n} / k_{s}$, and radius ratio of smaller particles at both ends of flat-joint $\lambda$; and the main macroparameters include elastic modulus $E$, Poisson ratio $v$, UCS $\sigma_{f}$, and TS $\sigma_{t}$.

2.2. Numerical Test of Intact Rock. In order to establish a PFC2D model that is close to the macroscopic behavior of the rock, the calibration of microparameters is the most important basic work. Considering that UCS/TS meets the actual values, uniaxial compression tests and direct tensile tests were carried out with numerical rock specimens of $100 \mathrm{~mm}$ in height and $50 \mathrm{~mm}$ in width, as shown in Figure 2. The loading rate of the uniaxial compression test is set to $0.01 \mathrm{~m} / \mathrm{s}$. $E, v$, and $\sigma_{f}$ can be obtained according to the stress-strain curve of the uniaxial compression test. The 


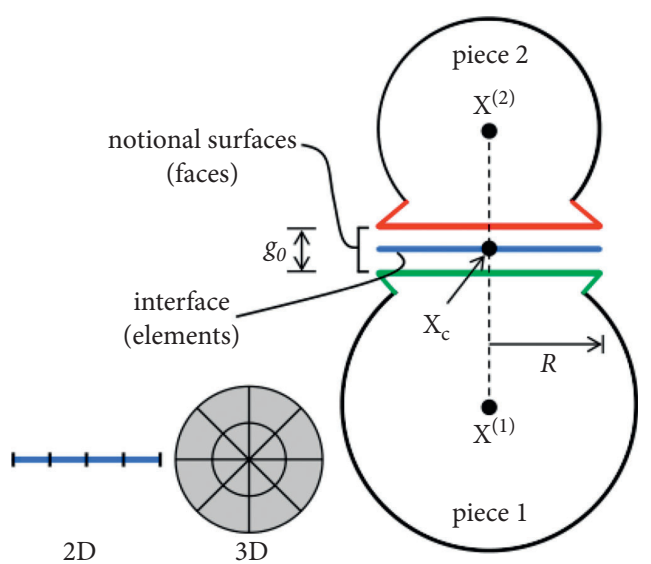

(a)

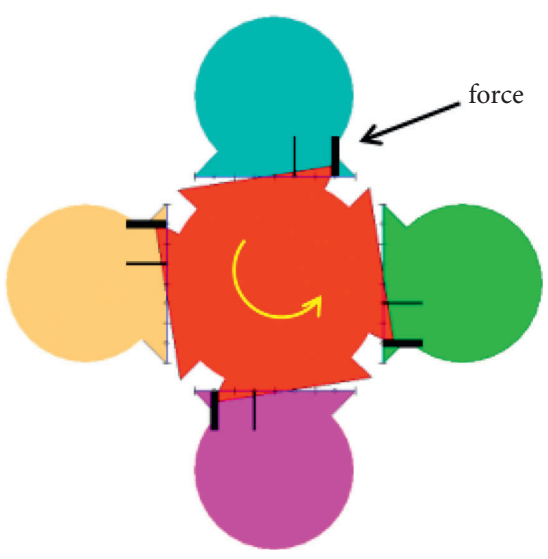

(b)

Figure 1: Flat-Joint Contact Model from Potyondy [15]. (a) Flat-Joint Contact. (b) Microstructure.

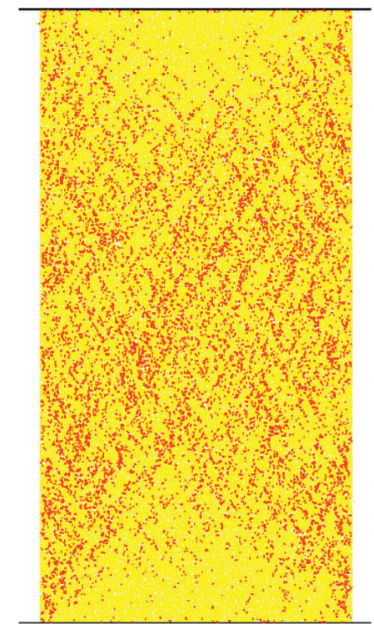

(a)

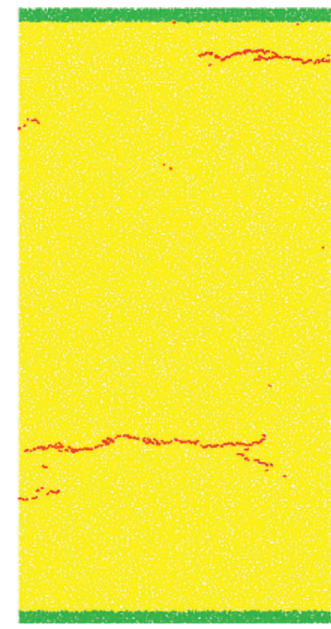

(b)

Figure 2: Numerical test of intact rock. (a) Uniaxial compression test. (b) Direct tension test.

peak stress of the stress-strain curve is the uniaxial compressive strength; the slope of the linear segment of the stress-strain curve is the elastic modulus; and Poisson's ratio is defined as the absolute value of the ratio of transverse strain to axial strain at $50 \%$ of the peak strength. The loading rate of the direct tension test is set to $0.005 \mathrm{~m} / \mathrm{s}$. $\sigma_{t}$ is determined from the peak strength of the specimen at rupture. The comparison of numerical test results with laboratory test results enables the calibration of microparameters.

2.3. Analysis of the Relationship between Macro- and Microparameters. The PFC2D model has a large number of microparameters, which can lead to a large number of numerical trials if the relationships between the macro- and microparameters are not understood when calibrating the microparameters. For this reason, this paper first investigated the relationship between the macro- and microparameters to provide a basis for the calibration of the microparameters so that they can be calibrated quickly and accurately.

2.3.1. Orthogonal Experimental Design. The FJCM in PFC2D has many microparameters, which would make parameter calibration exceptionally difficult if all microparameters were calibrated, and it is necessary to make some appropriate assumptions to reduce the difficulty of calibration. According to the research results of some scholars [17-20], it can be assumed that (1) $\mu=0.5$, (2) $N=4$, (3) $\lambda=1.66$, and (4) $\varphi=30^{\circ}$. The remaining four parameters outside the hypothesis were taken as the calibrated microparameters, and orthogonal tests were designed accordingly. The orthogonal test design is shown in Table 1, and the sequence of orthogonal design matrices is shown in Table 2. Macroparameters $E, v, \sigma_{f}$ and $\sigma_{t}$ were obtained from the uniaxial compression test and the direct tensile test, respectively, and the specific results are shown in Table 2. It can also be seen from Table 2 that UCS/TS 
TABLE 1: Orthogonal experimental design of FJCM microparameter.

\begin{tabular}{lcccc}
\hline Factor level & $E_{c}(\mathrm{GPa})$ & $k_{n} / k_{s}$ & $\sigma_{c}(\mathrm{MPa})$ & $c(\mathrm{MPa})$ \\
\hline 1 & 15 & 1.0 & 10 & 20 \\
2 & 30 & 1.5 & 20 & 30 \\
3 & 45 & 2.0 & 20 & 40 \\
4 & 60 & 2.5 & 25 & 50 \\
\hline
\end{tabular}

TABle 2: Orthogonal design matrix sequence and macroparameter calculation results of FJCM microparameter.

\begin{tabular}{|c|c|c|c|c|c|c|c|c|c|}
\hline \multirow{2}{*}{ No. } & \multicolumn{4}{|c|}{ Microparameters } & \multicolumn{5}{|c|}{ Macroparameters } \\
\hline & $E_{c}(\mathrm{GPa})$ & $k_{n} / k_{s}$ & $\sigma_{c}(\mathrm{MPa})$ & $c(\mathrm{MPa})$ & $E(\mathrm{GPa})$ & $v$ & $\sigma_{f}(\mathrm{MPa})$ & $\sigma_{t}(\mathrm{MPa})$ & $\sigma_{f} / \sigma_{t}$ \\
\hline 1 & 15 & 1.0 & 10 & 20 & 28.91 & 0.15 & 29.49 & 2.12 & 13.91 \\
\hline 2 & 15 & 2.5 & 15 & 40 & 11.41 & 0.29 & 52.84 & 3.04 & 17.38 \\
\hline 3 & 45 & 1.0 & 15 & 50 & 37.94 & 0.14 & 63.58 & 2.63 & 24.17 \\
\hline 4 & 15 & 2.0 & 25 & 30 & 11.86 & 0.25 & 48.60 & 5.10 & 9.53 \\
\hline 5 & 30 & 1.5 & 15 & 30 & 24.00 & 0.20 & 45.58 & 3.06 & 14.90 \\
\hline 6 & 30 & 2.5 & 20 & 20 & 22.11 & 0.27 & 39.38 & 4.06 & 9.70 \\
\hline 7 & 15 & 1.5 & 20 & 50 & 12.50 & 0.20 & 63.66 & 4.26 & 14.94 \\
\hline 8 & 45 & 2.0 & 20 & 40 & 34.11 & 0.22 & 64.72 & 3.91 & 16.55 \\
\hline 9 & 60 & 1.5 & 10 & 40 & 46.28 & 0.17 & 55.34 & 2.04 & 27.13 \\
\hline 10 & 60 & 2.5 & 25 & 50 & 42.43 & 0.25 & 80.32 & 4.73 & 16.98 \\
\hline 11 & 45 & 1.5 & 25 & 20 & 35.98 & 0.17 & 40.48 & 4.31 & 9.39 \\
\hline 12 & 60 & 1.0 & 20 & 30 & 46.42 & 0.15 & 50.92 & 4.30 & 11.84 \\
\hline 13 & 30 & 1.0 & 25 & 40 & 26.25 & 0.13 & 61.88 & 5.11 & 12.11 \\
\hline 14 & 45 & 2.5 & 10 & 30 & 32.83 & 0.24 & 45.69 & 1.80 & 25.38 \\
\hline 15 & 30 & 2.0 & 10 & 50 & 23.37 & 0.23 & 56.90 & 1.69 & 33.67 \\
\hline 16 & 60 & 2.0 & 15 & 20 & 44.23 & 0.20 & 40.48 & 2.58 & 15.69 \\
\hline
\end{tabular}

is overwhelmingly greater than 10 , which meets the requirements of the real rock.

2.3.2. Multifactor Analysis of Variance. Multifactor analysis of variance (MANOVA) can be used to investigate whether multiple factors have a significant effect on the dependent variable. By considering the main effects of each factor, the data in Table 2 are used to investigate whether the microparameters have a significant effect on the macroparameters via MANOVA. In MANOVA, the F-statistic can be used to compare the degree of influence of microparameters on macroparameters. The relative $F$-statistic is used to compare the degree of influence of each microparameter and is calculated as follows:

$$
f_{i}=\frac{F_{i}}{\sum_{1}^{n} F_{i}},
$$

where $f_{\mathrm{i}}$ is the relative $F$-statistic and $n$ is the number of microparameters.

The calculated F-statistic for MANOVA is shown in Figure 3 . The table of critical values for the $F$-statistic shows that $F_{0.05}(3,12)=3.49$ at the significance level $\alpha=0.05$. Therefore, when the $F$-statistic value is greater than 3.49 , the factor is considered to have a significant effect on the results. Accordingly, it can be concluded that for FJCM, $E$ is mainly influenced by $E_{c}$ and $k_{n} / k_{s}$, with $E_{c}$ having a much greater effect than $k_{n} / k_{s}$ and the remaining two having a small effect on $E$; only $k_{n} / k_{s}$ has a significant effect on $v$, with the remaining factors having little effect; $\sigma_{f}$ is influenced by $\sigma_{c}$ and $c$, and the effect of $\sigma_{c}$ is significantly greater than $c ; E_{c}, \sigma_{c}$, and $c$ all have a significant effect on $\sigma_{t}$, but the degree of influence $\sigma_{c}$ on $\sigma_{t}$ is absolutely dominant and significantly greater than the other two.

2.3.3. Regression Analysis. Based on the above numerical simulation results, the relationship between the macro- and microparameters was established as shown in Table 3.

As can be seen from Table 3,E is positively correlated with $E_{c}$ and negatively correlated with $k_{n} / k_{s} ; v$ is positively correlated with $k_{n} / k_{s}$; $\sigma_{f}$ is positively correlated with $\sigma_{c}$ and also positively correlated with $c$; and $\sigma_{t}$ is positively correlated with only $\sigma_{c}$. When performing the parameter calibration, the microparameters are initially calculated according to the fitting formula, and numerical tests are then carried out to calculate the macroparameters. Comparing the difference between the calculated and actual macroparameters and according to the trend relationship between the macro- and microparameters reflected in the fitting formula, the microparameters can be fine-tuned appropriately until a reasonable range of accuracy is achieved.

\section{Numerical Tests on Jointed Rock Masses}

3.1. Numerical Model. The establishment of the numerical model mainly refers to literature [4]. A rectangular rock specimen with dimensions of $2 \mathrm{~m}$ height and $1 \mathrm{~m}$ width was created by PFC2D. The minimum particle radius was set to $1.5 \mathrm{~mm}$; the ratio of maximum and minimum particle radius 


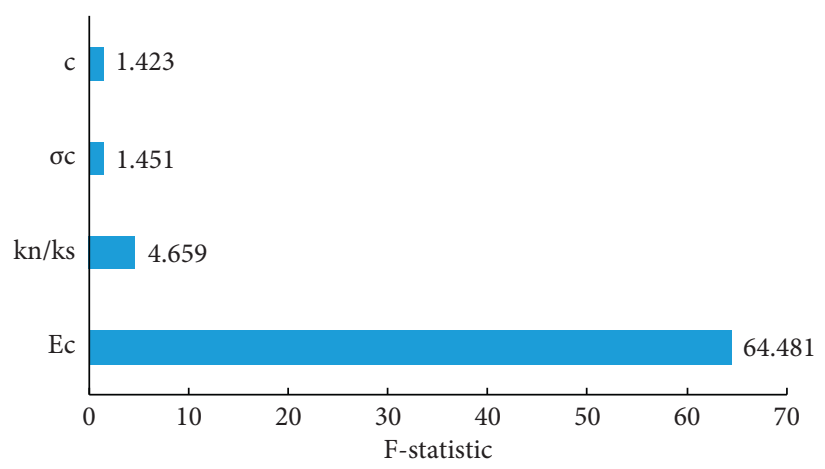

(a)

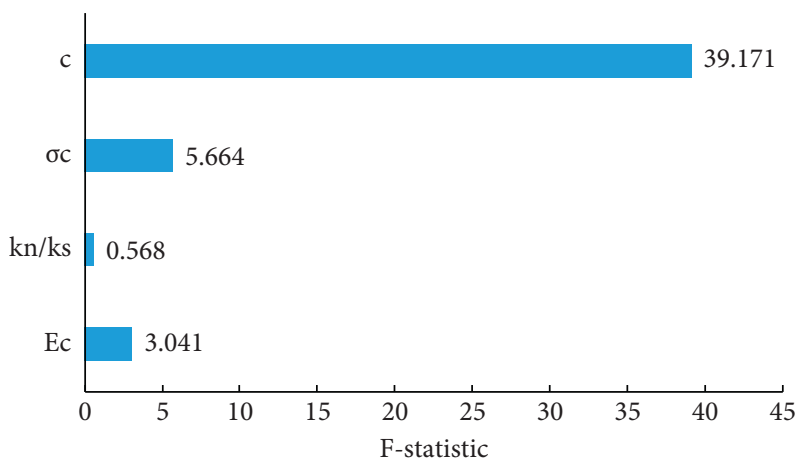

(c)

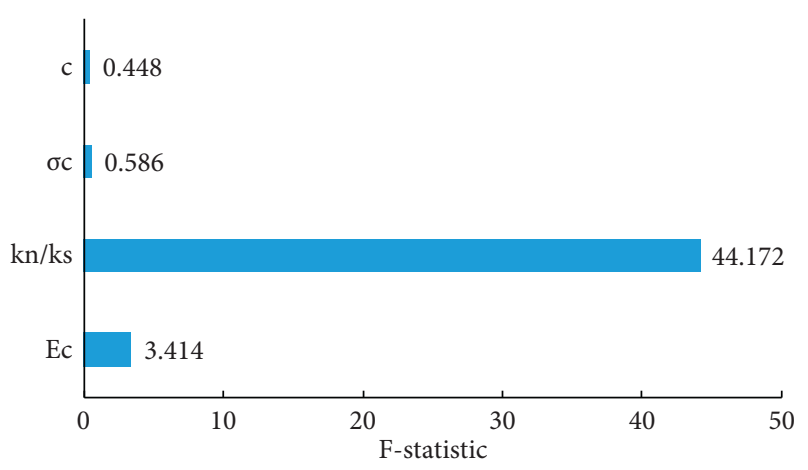

(b)

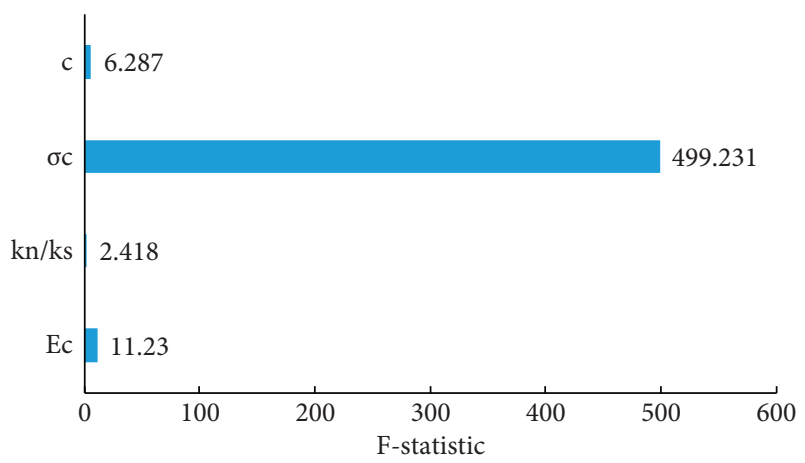

(d)

FIGURE 3: F-statistics of multivariate analysis of variance. (a) E. (b) $v$. (c) $\sigma_{f}$ (d) $\sigma_{t}$.

TABLE 3: Fitting formula between macro- and microparameters.

\begin{tabular}{lc}
\hline \multirow{2}{*}{ Fitting formula } & Coefficient of determination \\
& $R^{2}$ \\
\hline$E=0.649 E_{c}-4.871 k_{n} / k_{s}+14.24$ & 0.934 \\
$v=0.08 k_{n} / k_{s}+0.064$ & 0.890 \\
$\sigma_{f}=0.739 \sigma_{c}+0.97 c+5.621$ & 0.902 \\
$\sigma_{t}=0.2 \sigma_{c}-0.08$ & 0.947 \\
\hline
\end{tabular}

was set to 1.66 , the particle distribution within the model was adjusted by the radius expansion method, and the contact between the particles was set to FJCM. The Smooth-Joint Contact Model (SJCM) simulates the macroscopic behavior of joints among several particles. It was then introduced into the rock to generate the SRM specimens. The mechanical properties of SJCM are normal stiffness of $10^{10} \mathrm{~Pa}$, shear stiffness of $10^{11} \mathrm{~Pa}$, friction coefficient of 0.58 , and both tensile strength and cohesion of $0 \mathrm{~Pa}$. A total of seven types of specimens were generated, namely, single-, double-, triple-, and quadruple-jointed specimens and others with joint dip angle of $30^{\circ}, 45^{\circ}$, and $60^{\circ}$. The macroparameters of rock published in literature [21] and the microparameters determined by the calibration equations in Section 2 are shown in Table 4. All the errors in the calculated values of the macroparameters compared to the test values are less than $6 \%$ (see Table 5), indicating that the calibration of the microparameters is reliable.

Each rock mass specimen was impacted eight times, and the impact velocity $V$ of the rigid ball with $0.4 \mathrm{~m}$ diameter and the density of $2700 \mathrm{~kg} / \mathrm{m}^{3}$ was $30 \mathrm{~m} / \mathrm{s}$ for each impact.
TABle 4: Microparameters based on FJCM.

\begin{tabular}{llllcccc}
\hline Microparameters & $N$ & $\mu$ & $\begin{array}{c}\Phi \\
\left({ }^{\circ}\right)\end{array}$ & $\begin{array}{c}E_{c} \\
(\mathrm{GPa})\end{array}$ & $\begin{array}{c}k_{n} / \\
k_{s}\end{array}$ & $\begin{array}{c}\sigma_{c} \\
(\mathrm{MPa})\end{array}$ & $\begin{array}{c}c \\
(\mathrm{MPa})\end{array}$ \\
\hline Calibration value & 4 & 0.5 & 30 & 102 & 2.45 & 46.9 & 181 \\
\hline
\end{tabular}

TABle 5: Comparison between experimental test results and the FJCM simulation.

\begin{tabular}{lcccc}
\hline Mechanical parameters & $\sigma_{f}(\mathrm{MPa})$ & $E(\mathrm{GPa})$ & $v$ & $\sigma_{t}(\mathrm{MPa})$ \\
\hline Test results & 216 & 69 & 0.26 & 9.3 \\
Numerical results & 205 & 69.3 & 0.245 & 9.56 \\
Relative error (\%) & 5.1 & 0.43 & 5.7 & 2.8 \\
\hline
\end{tabular}

Taking a single joint as an example, the numerical model of the impact test is schematically shown in Figure 4, and the boundary condition of the calculation model is that no horizontal and vertical displacement occurs at the bottom. The change in the number of cracks and the energy loss were recorded during each impact.

3.2. Effect of the Number of Horizontal Joints. In order to investigate the influence of the number of horizontal joints on the repetitive impact damage of rock masses, numerical tests were conducted on rock masses containing one, two, and three joints, respectively. Figure 5 shows the distribution of impact-induced cracks as a quantitative parameter for rock mass damage assessment in the $1^{\text {st }}, 3^{\text {rd }}, 5^{\text {th }}$, and $7^{\text {th }}$ 


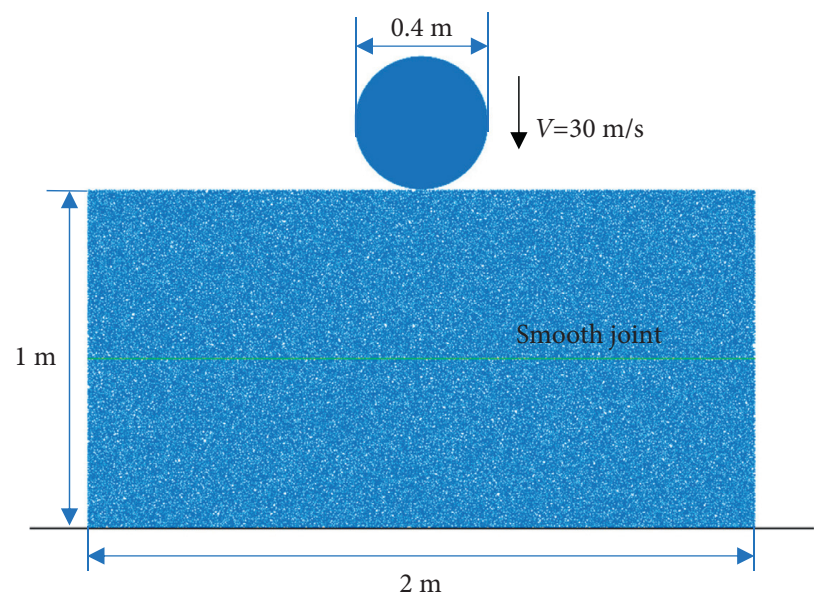

FIgURE 4: Schematic diagram of impact test.

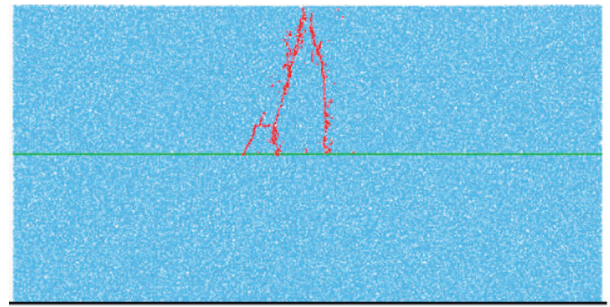

1 st

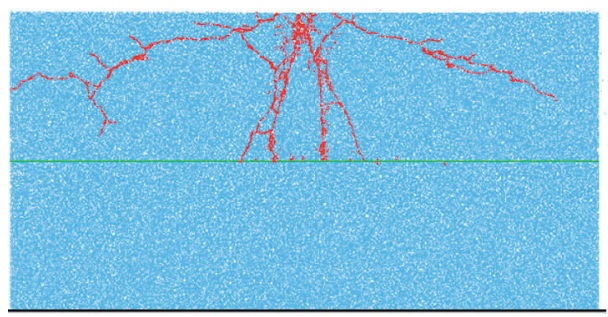

5th

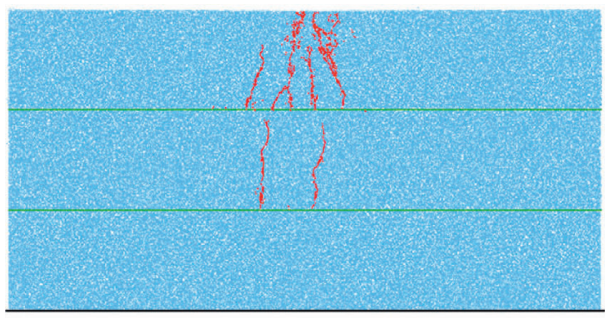

1 st

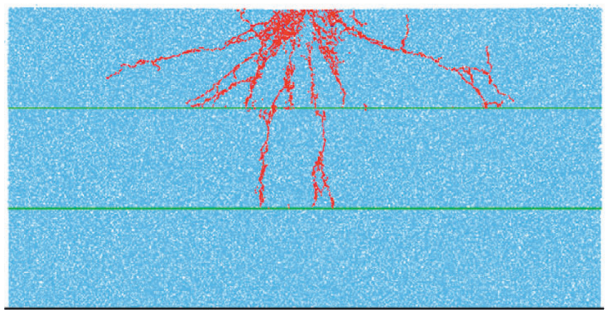

5th

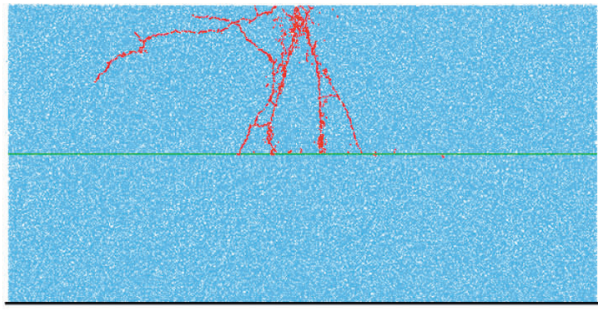

$3 r d$

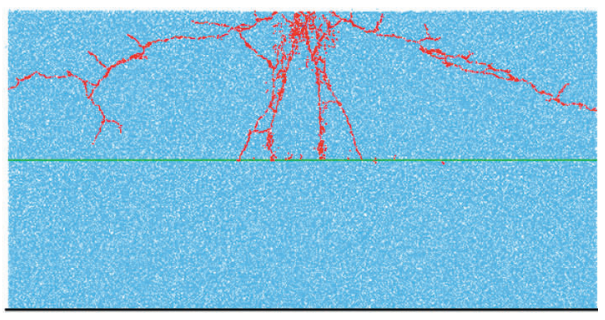

7th

(a)
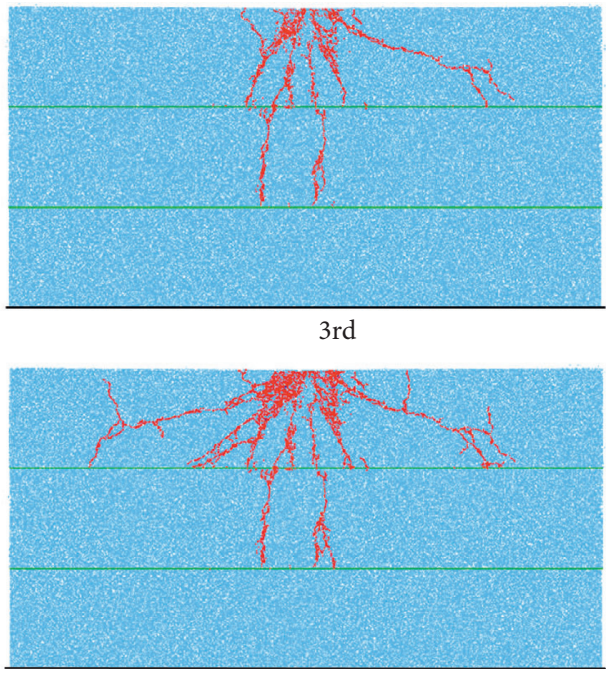

7th

(b)

Figure 5: Continued. 


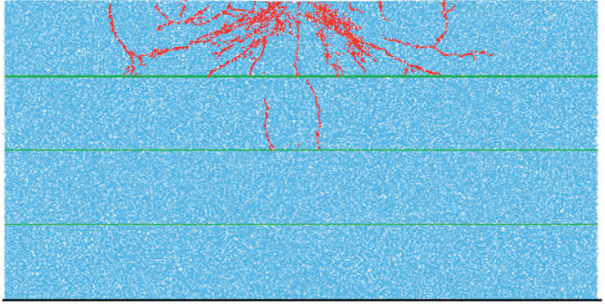

1st

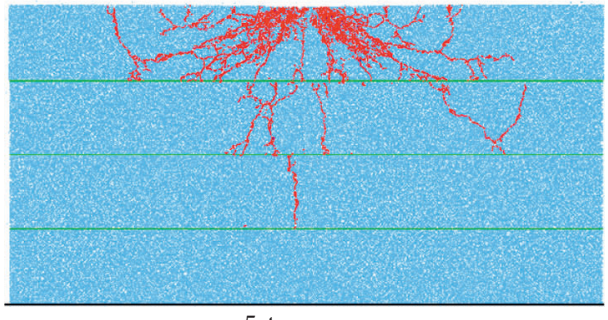

5 st

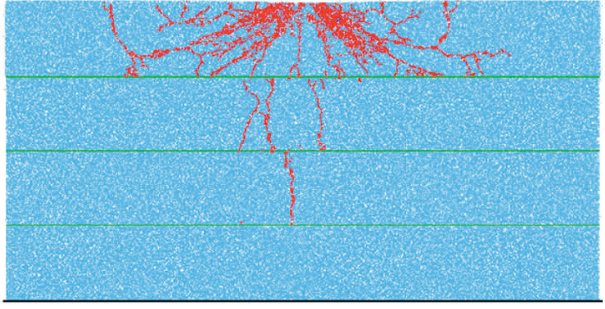

3 st

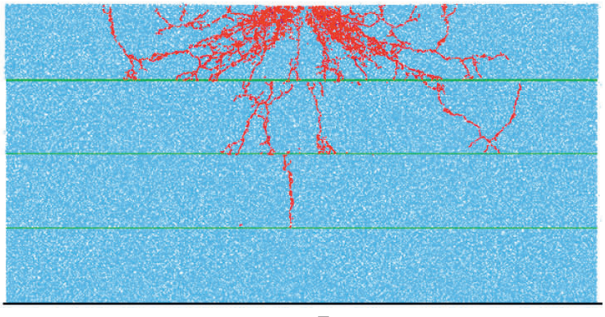

$7 \mathrm{st}$

(c)

Figure 5: Impact-induced damage within the rock mass specimens with different horizontal joint numbers. (a) Single-jointed. (b) Double-jointed. (c) Triple-jointed.

impact, and tension and shear cracks are indicated in red and black, respectively. The spatial combination pattern of these microcracks shows the macroscopic damage and fracture propagation distribution of the rock mass. Shear and tensile cracks are produced within the jointed rock masses, with tensile cracks predominating, with the greatest density of cracks at the point of impact. When impacted, the microcracks propagate symmetrically from the point of impact downwards and upwards from the preexisting joints at the same time, and then the propagation paths gradually coalesce. The absence of microcracks below the preexisting joints means that the cracks only develop to the sides but never propagate longitudinally across the preexisting joints; that is, the crack propagation path is blocked when reaching the joints, which is consistent with the findings of literature [22]. The microcracks produced by the first two impacts are mainly radial cracks, and transverse cracks appear from the $3^{\text {rd }}$ impact. However, the cracks only propagate along the impact point towards the left boundary until the $5^{\text {th }}$ impact when the cracks start to propagate along the impact point towards the right boundary. From the $6^{\text {th }}$ impact onwards, there is no significant change in crack propagation. The degree of damage to the SRM specimen is gradually stabilized, with the cracks eventually showing an "umbrella" distribution.

With the single-jointed specimen, the cracks of doublejointed specimen also propagate simultaneously from the preexisting joints and the impact point. The cracks in the double-jointed specimen propagate mainly in the radial direction on the first two impacts. Laterally expanding cracks start to appear on the third impact, after which the crack propagation is similar to that of the single-jointed specimen. The cracks develop symmetrically, with the greatest density of cracks at the point of impact, and the cracks stop continuing to propagate at the preexisting joint furthest from the impact point. A large number of cracks, both transverse and radial, are produced in the triple-jointed specimen after the first impact. After that, cracks continue to be produced near the impact point, and relatively few radial cracks continue to propagate. Finally, the cracks are also interrupted at the preexisting joint furthest from the impact point. Compared to the single-jointed specimen, the doubleand triple-jointed specimens are subjected to repetitive impacts with a significantly larger area of fragmentation and a significantly greater number of cracks. Figure 6 shows a relationship between the crack number and the impact number of three types of specimens. From the $6^{\text {th }}$ impact, the slope of all three curves decreases significantly, indicating that the crack growth rate is gradually slowing down from the $6^{\text {th }}$ impact onwards, which is also confirmed by the test results in Figures 5 and 6 . If the number of impacts continues to increase, the slope will tend to zero and the number of cracks will almost cease to change, which explains why the impact number was chosen to be 8 .

Each impact test consists of loading and unloading phases. When the rigid ball is in contact with the rock mass specimen, it is regarded as the beginning of the loading process. After that, the energy of the rigid ball is gradually absorbed, and the speed gradually decreases. When the speed of the rigid ball drops to 0 , the loading process is completely finished. Then, the unloading process starts immediately when the rigid ball begins to rebound from the specimen surface. In this simulation, the loading process refers to the first 15,000 cycles, followed by the unloading process. The change in particle velocity during the first impact loading and unloading of a single-jointed specimen is shown in Figure 7, and the stress wave propagation inside the rock mass is reflected by the change in particle velocity, which is recorded once every 5000 cycles. When the impact starts, the stress wave propagates outwards in a circular pattern from the impact point. When the stress wave comes into contact with the joint surface, the presence of the joint 


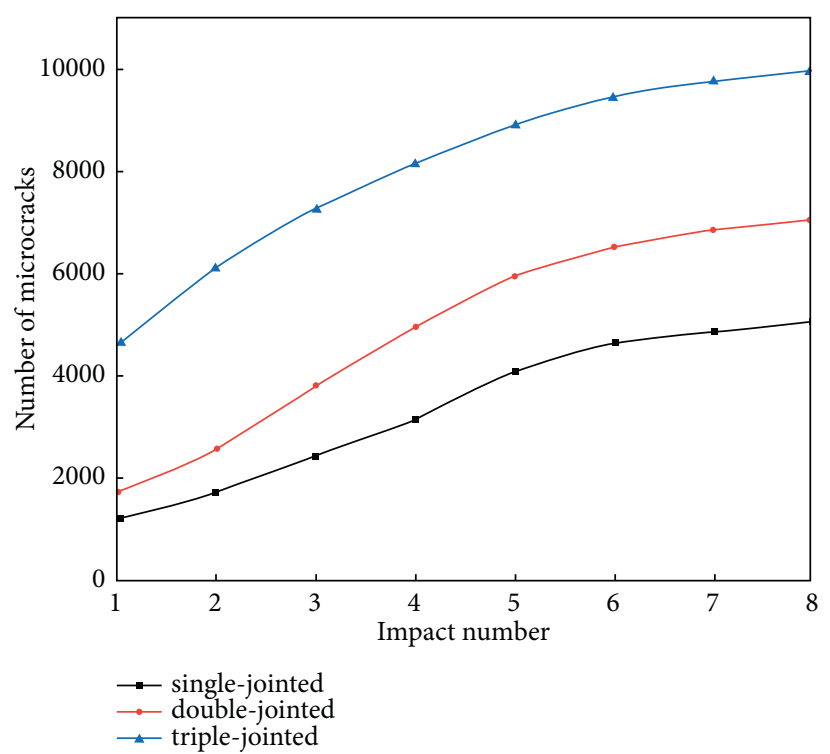

FIGURE 6: Relationship between the crack number and the impact number for rock mass specimens with different horizontal joint numbers.

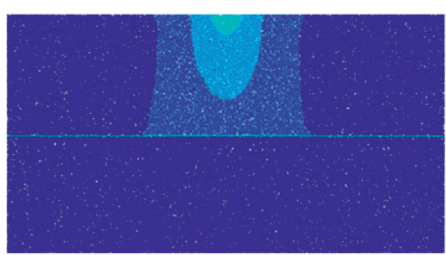

cycle $=5000$

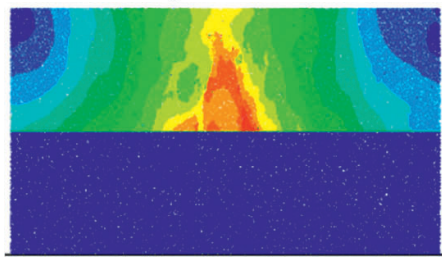

cycle $=20000$

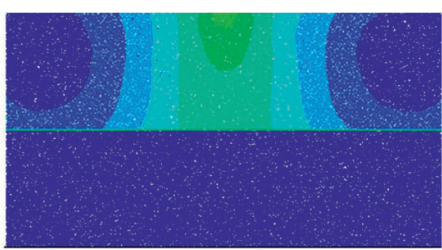

cycle $=10000$

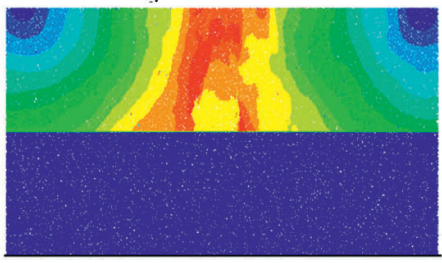

cycle $=25000$

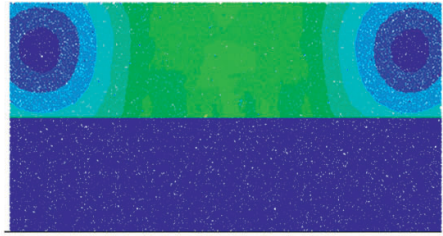

cycle $=15000$

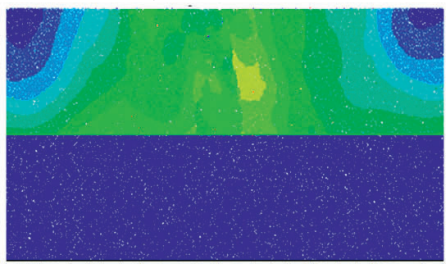

cycle $=30000$
Ball velocity_mag

$2.0000 \mathrm{E}+00$

$1.9500 \mathrm{E}+00$

$1.8000 \mathrm{E}+00$

$1.6500 \mathrm{E}+00$

$1.5000 \mathrm{E}+00$

$1.3500 \mathrm{E}+00$

$1.2000 \mathrm{E}+00$

$1.0500 \mathrm{E}+00$

9.0000E-01

$7.5000 \mathrm{E}-01$

$6.0000 \mathrm{E}-01$

$4.5000 \mathrm{E}-01$

$3.0000 \mathrm{E}-01$

$1.5000 \mathrm{E}-01$

$0.0000 \mathrm{E}+00$

Figure 7: Particle velocity of single-jointed specimen.

(a) Cycle $=5000$.

(b) Cycle $=10000$

(c) Cycle $=15000$.

(d) Cycle $=20000$.

(e) Cycle $=25000$. (f) Cycle $=30000$.

blocks the path of the stress wave propagation, and the stress wave is reflected and transmitted at the joint surface. As the elastic modulus of the joints is much lower than that of the rock, the transmission is small and the reflection is dominant. When the reflected waves meet the downward following stress waves and the lateral reflected waves, the stress waves will change from compressional waves to tensile waves. The tensile strength of the rock is much lower than the compressive strength, resulting in easy damage in the tensile region so that cracks first start at the joints and gradually propagate upwards, corresponding to Figure 5(a).

Energy dissipation occurs during the entire impact process. In the loading stage, the kinetic energy of the system decreases after the rigid ball contacts the rock mass specimen. When the velocity of the rigid ball is 0 , the kinetic energy of the system is close to 0 and almost all kinetic energy is transformed into strain energy. In the unloading stage, strain energy is gradually transformed into kinetic energy again; but the kinetic energy at this time is less than the initial kinetic energy of the system due to the frictional slip between particles, the fragmentation of rock mass specimen, the collapse of particles, and the transformation of thermal energy.

The dissipated energy per unit area of jointed specimens after each impact is compared, as shown in Figure 8. Overall, the greater the number of joints, the greater the energy dissipated by impact. For single- and double-jointed rock masses, the energy dissipated per unit area shows a clear three-stage pattern as the number of impacts increases. The first stage is the decreasing stage, corresponding to the $1^{\text {st }}$ and $2^{\text {nd }}$ impacts, in which the energy dissipated per unit area is relatively high after each impact and then decreases with the increase of the number of impacts. The second stage is the stable stage, in which the energy dissipated per unit area of the rock mass cannot change much, and the curve is almost a straight line, corresponding to the $3^{\text {rd }}, 4^{\text {th }}$, and $5^{\text {th }}$ 


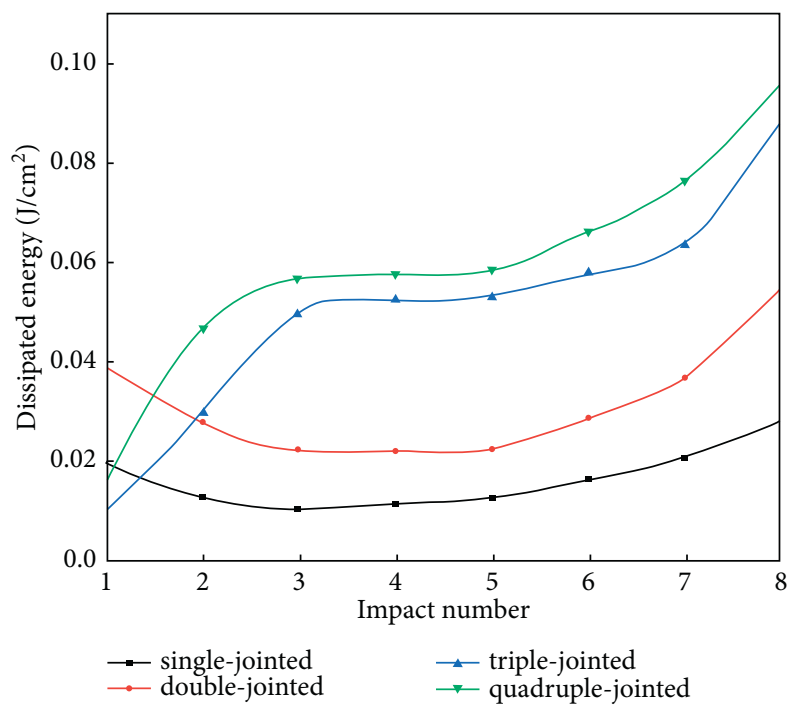

Figure 8: Relationship between the dissipated energy and the impact number for rock mass specimens with a different horizontal joint number.

impacts. The energy dissipated per unit area of single- and double-jointed specimens in this stage is $0.0116 \mathrm{~J} / \mathrm{cm}^{2}$ and $0.0221 \mathrm{~J} / \mathrm{cm}^{2}$, respectively. The third stage is the rising stage, corresponding to the $6^{\text {th }}, 7^{\text {th }}$, and $8^{\text {th }}$ impacts. In this stage, with the increase of the impact number, more blocks fall, and the ejection distance of broken rock blocks is longer. Hence, the energy dissipation per unit area of each impact increases significantly. The relationship between the dissipated energy and the impact number is nonlinear, the increasing rate becomes larger successively, and the rate of double-jointed specimen is greater than that of single-jointed specimen. The energy dissipation pattern of single- and double-jointed specimens is consistent with the results of $\mathrm{Li}$ et al. [6].

The dissipated energy per unit area of triple-jointed specimen is in the rising phase at the $1^{\text {st }}$ and $2^{\text {nd }}$ impacts. Then, the dissipated energy enters the stable phase, and its value is $0.055 \mathrm{~J} / \mathrm{cm}^{2}$ per impact, which is significantly greater than that of the single- and double-jointed specimens. Finally, the dissipated energy changes again to the rising phase at the $7^{\text {th }}$ and $8^{\text {th }}$ impacts. The reason for this situation is that the triple-jointed specimen produces a large number of cracks immediately after the $1^{\text {st }}$ impact, which makes the rock structure extremely unstable. The damage of the rock mass increases rapidly during the $2^{\text {nd }}$ impact, the development of cracks dissipates a large amount of energy, and the capacity of the rock mass to store elastic energy decreases. Therefore, the dissipated energy increases. To further illustrate this phenomenon, a diagram of energy dissipation in a quadruple-jointed specimen is also given in Figure 8, which is similar to that of triple-jointed specimen, thus confirming the reasonableness of the above inference.

3.3. Effect of Joint Orientation. The impact-induced damage of rock masses depends not only on the number of joints but also on their orientation. In order to investigate the effect of joint orientation on the repetitive impact damage of rock masses, simulations on SRM specimens with joint dip angles $\left(\alpha=30^{\circ}, 45^{\circ}\right.$, and $\left.60^{\circ}\right)$ were carried out, respectively. Figure 9 shows the macroscopic damage and crack propagation distribution of the rock mass. At the end of the first impact, a large number of cracks are produced at the impact point, mainly along the direction of the preexisting joints, and a small number of cracks perpendicular to the direction of the preexisting joints also appear. In the next few impacts, the cracks propagate mainly perpendicular to the direction of the preexisting joints. After the third impact, a small number of cracks begin to appear at the base of the rock mass. Finally, the upper and lower cracks slowly propagate and gradually coalesce.

It is clear from Figure 9 that the number of cracks decreases with the joint dip angle increasing. The damage pattern for the $45^{\circ}$ joint specimen is similar to that with the $30^{\circ}$, with the greatest density of crack distribution at the point of impact, after which the cracks propagate mainly in a direction perpendicular to the preexisting joints. The difference is that the cracks between the top and the bottom of the $45^{\circ}$ joint cannot achieve to the extent that they can coalesce each other. The failure pattern of the $60^{\circ}$ joint differs from the first two, and the greatest density of crack distribution is at the bottom, where one of the preexisting joints intersects the wall. After the third impact, the crack density at the impact point has remained almost constant and the crack density at the bottom starts to increase rapidly, but the cracks cannot appear to propagate across the joints. Figure 10 shows the relationship between the number of cracks and the impact number for the three cases. It can be seen that the number of cracks decreases as the dip angle of the joints increases, and the rate of crack growth is significantly greater for the $30^{\circ}$ joint than for the other two because the joints reduce the crack propagation space and inhibit vertical crack propagation. The slope of all three curves decreases significantly from the $6^{\text {th }}$ impact onwards. The slope of all three curves decreases significantly from the $6^{\text {th }}$ impact, indicating 


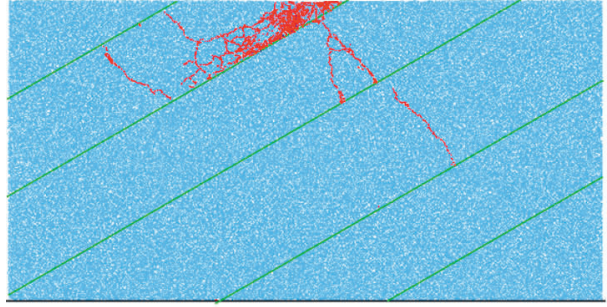

1 st

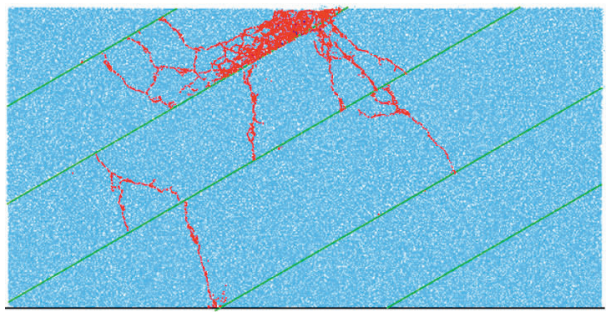

5th

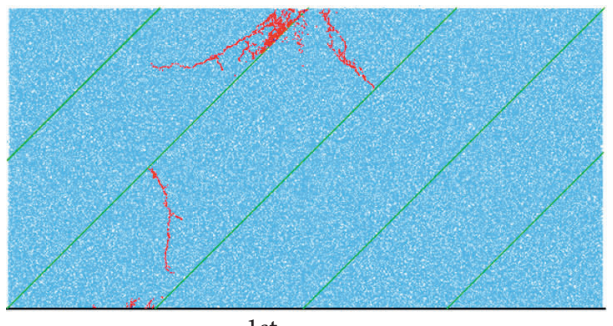

1 st

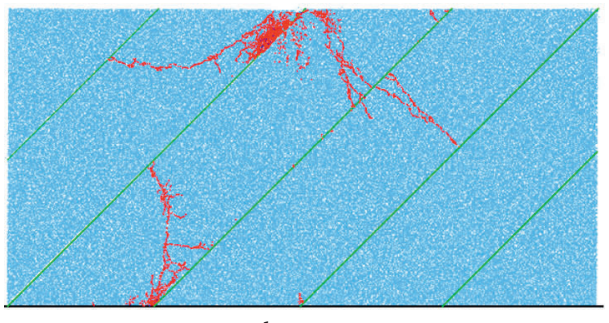

5th

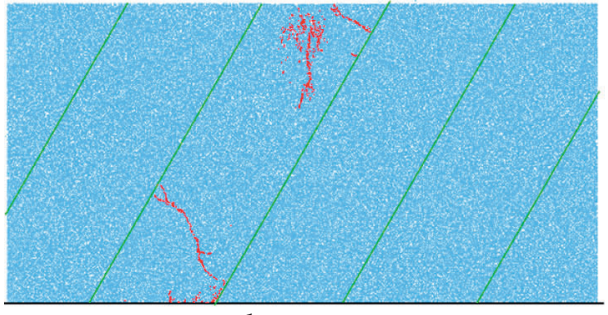

1st

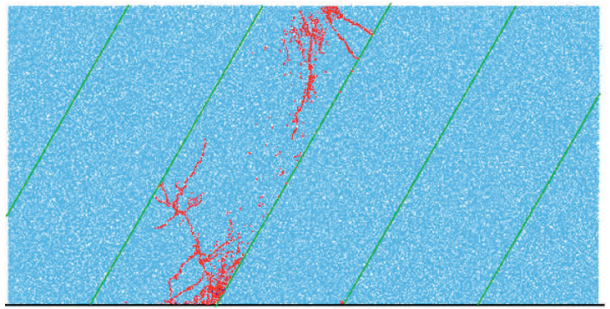

5th

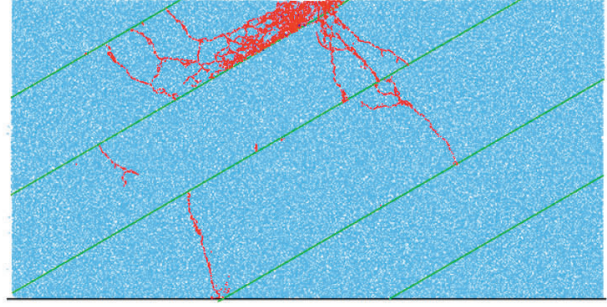

3rd

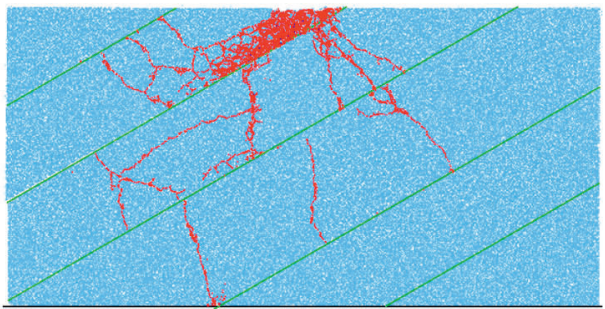

7th

(a)
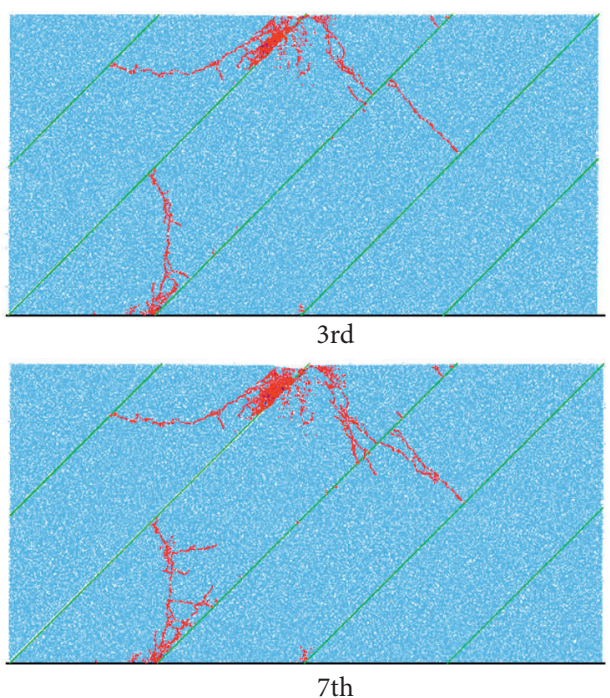

(b)
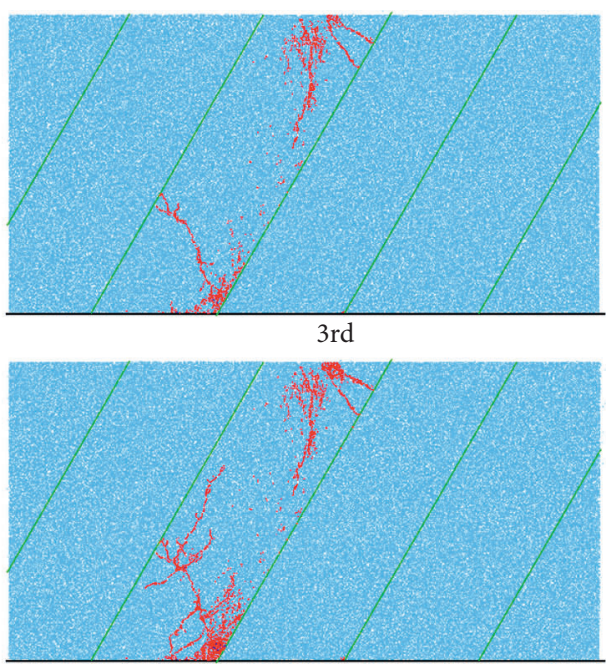

7th

(c)

FIGURE 9: Impact-induced damage within the rock mass specimens with different joint dip angles. (a) $\alpha=30^{\circ}$. (b) $\alpha=45^{\circ}$. (c) $\alpha=60^{\circ}$. 


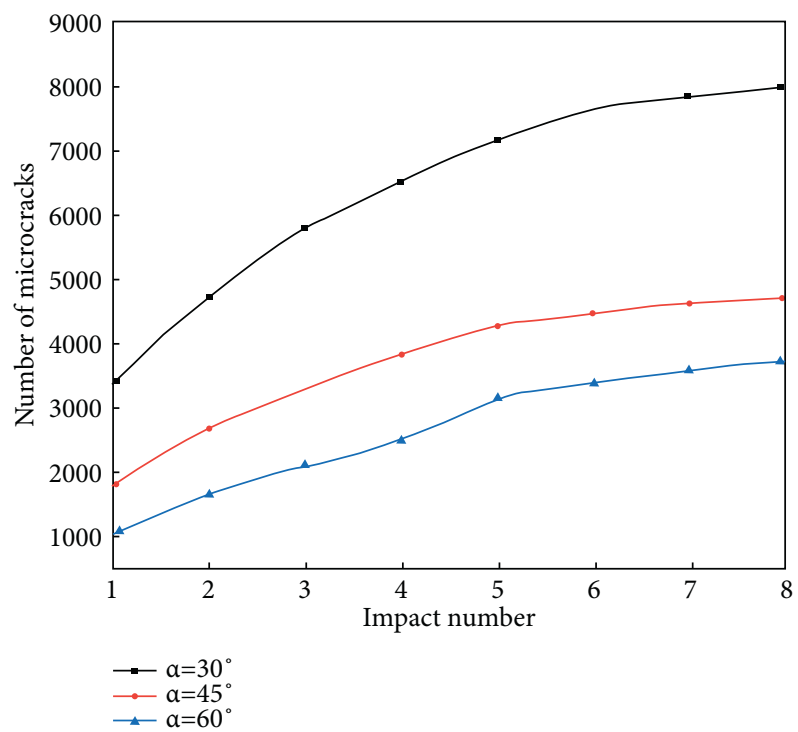

FiguRE 10: Relationship between the crack number and the impact number for rock mass specimens with different joint dip angles.

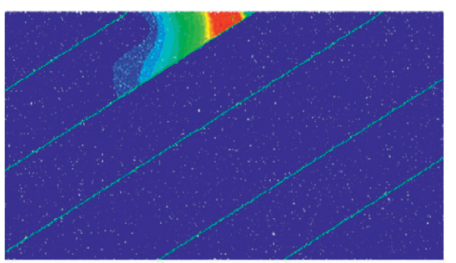

cycle $=5000$

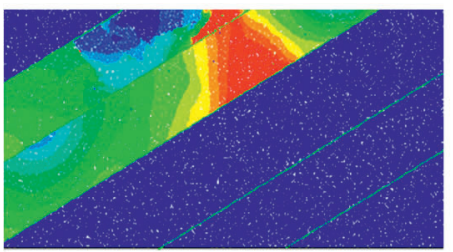

cycle $=20000$

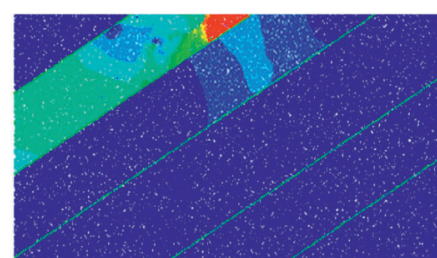

cycle $=10000$

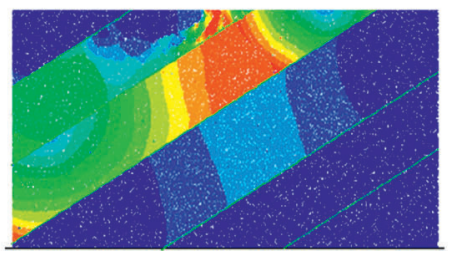

cycle $=25000$

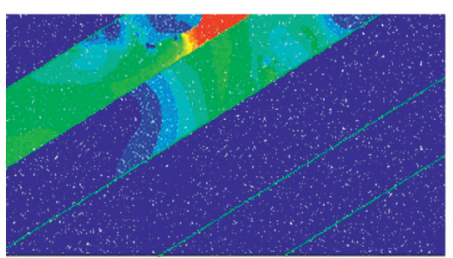

cycle $=15000$

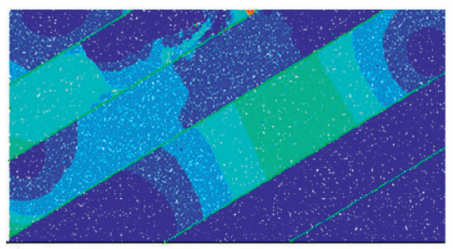

cycle $=30000$
Ball velocity_mag

$2.0000 \mathrm{E}+00$

$1.9500 \mathrm{E}+00$

$1.8000 \mathrm{E}+00$

$1.6500 \mathrm{E}+00$

$1.5000 \mathrm{E}+00$

$1.3500 \mathrm{E}+00$

$1.2000 \mathrm{E}+00$

$1.0500 \mathrm{E}+00$

$9.0000 \mathrm{E}-01$

$7.5000 \mathrm{E}-01$

$6.0000 \mathrm{E}-01$

4.5000E-01

$3.0000 \mathrm{E}-01$

$1.5000 \mathrm{E}-01$

$0.0000 \mathrm{E}+00$

Figure 11: Particle velocity of $30^{\circ}$ joint specimen.

that the rate of increase in crack numbers is gradually slowing down from the $6^{\text {th }}$ impact onwards.

The dip angle of the joints has a significant effect on stress wave propagation. Figure 11 shows the process of stress wave propagation in a rock mass with a joint dip angle of $30^{\circ}$. After the impact starts, the stress waves also start to propagate outwards from the impact point and soon reach the No. 1 joint face. Some of the stress waves reflected by the joint face propagate upwards as a whole, easily forming a tensile damage zone with subsequent stress waves on the upper part of the joint face and developing through cracks. Due to the large stress waves reaching the No. 1 joint face, some of the stress waves are transmitted and propagated to No. 2 and even No. 3 joints, resulting in tensile cracks perpendicular to No. 2 and No. 3 joints, as Figure 9(a) verifies this statement.

The dissipated energy per unit area after each impact is shown in Figure 12 for the three different dip angle joints. In general, $30^{\circ}$ jointed rock mass has the deepest crack propagation, the largest area of fragmentation, and the most dissipated energy, while $60^{\circ}$ has the smallest area of fragmentation and the least dissipated energy. The dissipated energy by impact decreases gradually as the joint dip angle increases, and the three curves differ greatly in their trends. The $30^{\circ}$ curve is similar to the triple-joint curve shown in Figure 8 in that it only includes the rising and stable phases. The $45^{\circ}$ has three distinct phases: the falling phase of the $1^{\text {st }}$ impact, the stable phase of the $2^{\text {nd }}, 3^{\text {rd }}, 4^{\text {th }}$, and $5^{\text {th }}$ impacts and the rising phase of the $6^{\text {th }}, 7^{\text {th }}$, and $8^{\text {th }}$ impacts, which are similar to the results of the single- and double-jointed impacts shown in Figure 8 . For the $60^{\circ}$, it also contains a falling phase for the $1^{\text {st }}$ impact, a stabilizing phase for the $2^{\text {nd }}$, $3^{\text {rd }}, 4^{\text {th }}, 5^{\text {th }}$, and $6^{\text {th }}$ impacts, and an ascending phase for the $7^{\text {th }}$ and $8^{\text {th }}$ impacts. However, the transformation between the falling and ascending phases is not significant enough, and the dissipated energy is always at a relatively low level 


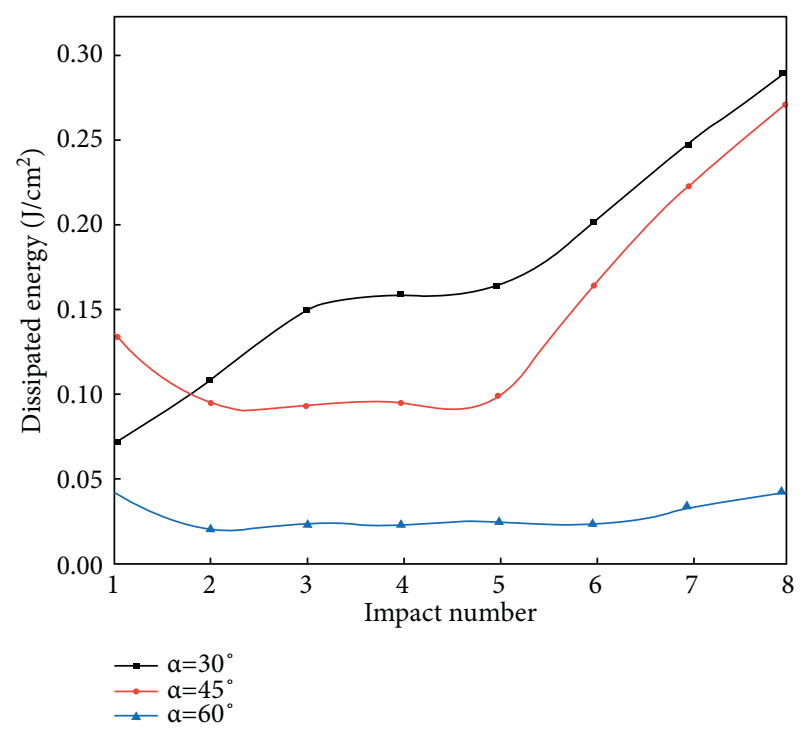

FIGURE 12: Relationship between the dissipated energy and the impact number for rock mass specimens with different joint dip angles.

\section{Conclusion}

Based on PFC2D, the relationship between the macro- and microparameters is firstly obtained by an orthogonal experimental design method in order to accurately calibrate the microparameters. Afterward, the repetitive impact numerical tests on rock masses specimens with different number and dip angle joints were carried out to study the damage evolution, stress wave propagation, and energy dissipation characteristics. The main conclusions are as follows:

(1) Under repetitive impact loading, the degree of damage to jointed rock mass is positively correlated with the number of horizontal joints and negatively correlated with the dip angle of the joints, and the crack growth rate slows down with the impact number. For horizontal joint specimens, the cracks are usually symmetrically distributed, and the density of cracks is greatest near the point of impact. Cracking starts with mainly radial extensional cracks, followed by transverse cracks as the radial cracks approach saturation. In all three cases, the radial cracks are propagated to the furthest preexisting joints from the impact point and are then cut off, indicating that the joints have a degree of cutoff effect on the crack propagation. For the $30^{\circ}$ and $45^{\circ}$ joint specimens, the cracks propagate along and perpendicular to the joint surface, with the greatest crack density at the point of impact; for the $60^{\circ}$ joint specimen, there are no cracks perpendicular to the joint surface, and the greatest crack density occurs at the base of the rock mass.

(2) In terms of energy dissipation, for horizontal joints, the dissipated energy per unit area is positively correlated with the number of joints. The same pattern of energy dissipation in single- and doublejointed rock masses includes descending, stabilizing, and ascending phases in that order. Triple- and quadruple-jointed are different from the first two including ascending, stabilizing and ascending phases in that order. The main reason is that the triple- and quadruple-jointed specimens are already severely damaged by the initial impact, making the rock extremely unstable. The dissipated energy per unit area is negatively correlated with the dip angle of the joints, and the general law is similar to that of the horizontal joint rock mass.

(3) The presence of joints affects the propagation of stress waves, which in turn affects the energy dissipation within the jointed rock mass. When the stress waves propagate to the joints, they encounter reflections. Then, when the reflected waves meet the subsequent stress waves and the lateral reflected waves, the stress waves will change from compressional waves to tensile waves, producing tensile damage within the rock mass.

\section{Data Availability}

The data used to support the findings of this study are available from the corresponding author upon request.

\section{Conflicts of Interest}

The authors declare no conflicts of interest.

\section{Acknowledgments}

This study was supported by the Zhejiang Collaborative Innovation Center for Prevention and Control of Mountain Geological Hazards (no. PCMGH-2017-Y-04).

\section{References}

[1] Y. F. Zhang, J. C. Li, and Y. T. Yan, "Experimental study on dynamic damage characteristics of roughness joint surface based on SHPB," Rock and Soil Mechanics, vol. 42, no. 2, pp. 491-500, 2021.

[2] C. L. Xiao, R. S. Yang, C. X. Ding et al., "Dynamic fracture experiment of medium with defects under impact loading," Shock And Vibration, vol. 2021, Article ID 8860929, 9 pages, 2021.

[3] H. X. Jiang, Z. Y. Cai, O. G. Wang, and D. Meng, "Experimental and Numerical Investigation of Hard Rock Breakage by Indenter Impact," Shock and Vibration, vol. 2020, Article ID 2747830, 12 pages, 2020.

[4] S. Aziznejad, K. Esmaieli, J. Hadjigeorgiou, and D. Labrie, "Responses of jointed rock masses subjected to impact loading," Journal of Rock Mechanics and Geotechnical Engineering, vol. 10, no. 4, pp. 624-634, 2018.

[5] X. B. Li, T. S. Lok, and J. Zhao, "Dynamic characteristics of granite subjected to intermediate loading rate," Rock Mechanics and Rock Engineering, vol. 38, no. 1, pp. 21-39, 2005.

[6] S. H. Li, W. C. Zhu, L. L. Niu, M. Yu, and C. F. Chen, "Dynamic characteristics of green sandstone subjected to repetitive impact loading: phenomena and mechanisms," 
Rock Mechanics and Rock Engineering, vol. 51, no. 6, pp. 1921-1936, 2018.

[7] Z. L. Wang, H. Yang, and N. C. Tian, "Mechanical property and damge evolution mechanism of granite under uniaxial cyclic impact," Journal of Harbin Institute of Technology, vol. 52, no. 2, pp. 59-66, 2020.

[8] B. Dai, X. Y. Luo, L. Chan et al., "Analysis on damage characteristics and energy dissipation of rock with a single hole under cyclic impact loads," China Safety Science Journal, vol. 2020, pp. 69-77, Article ID 8863645, 2020.

[9] G. H. Zheng, J. Y. Xu, and P. Wang, "Physical characteristics and degradation model of stratified sandstone under freezethaw cycling," Rock and Soil Mechanics, vol. 40, no. 2, pp. 632-641, 2019.

[10] L. Roy Xu, Y. G. Huang, and A. J. Rosakis, "Dynamic crack deflection and penetration at interfaces in homogeneous materials: experimental studies and model predictions," Journal of the Mechanics and Physics of Solids, vol. 51, no. 3, pp. 461-486, 2003.

[11] J. Qiu, D. Li, and X. Li, "Dynamic failure of a phyllite with a low degree of metamorphism under impact Brazilian test," International Journal of Rock Mechanics and Mining Sciences, vol. 94, pp. 10-17, 2017.

[12] C. Zou, L. N. Y. Wong, J. J. Loo, and B. S. Gan, "Different mechanical and cracking behaviors of single-flawed brittle gypsum specimens under dynamic and quasi-static loadings," Engineering Geology, vol. 201, no. 4, pp. 71-84, 2016.

[13] L. Zhou, Z. Zhu, Y. Dong, P. Ying, and M. Wang, "Study of the fracture behavior of mode I and mixed mode I/II cracks in tunnel under impact loads," Tunnelling and Underground Space Technology, vol. 84, pp. 11-21, 2019.

[14] F. Y. Liu, P. Y. Chen, and H. M. Yu, "PFC simulation of uniaxial compression and brazilian splitting test of rock based on flat-jointed bonded-particle material," Journal of Yangtze River Scientific Research Institute, vol. 33, no. 9, pp. 60-65, 2016.

[15] D. O. Potyondy and P. A. Cundall, "A bonded-particle model for rock," International Journal of Rock Mechanics and Mining Sciences, vol. 41, no. 8, pp. 1329-1364, 2004.

[16] N. Cho, C. D. Martin, and D. C. Sego, "A clumped particle model for rock," International Journal of Rock Mechanics and Mining Sciences, vol. 44, no. 7, pp. 997-1010, 2007.

[17] D. O. Potyondy, "A flat-jointed bonded-particle material for hard rock," in Proceedings of the 46th US Rock Mechanics Geomechanics Symposium, American Rock Mechanics Association, Chicago, USA, January 2012.

[18] M. Bahaaddini, A. M. Sheikhpourkhani, and H. Mansouri, "Flat-joint model to reproduce the mechanical behaviour of intact rocks," European Journal of Environmental and Civil Engineering, vol. 25, no. 8, pp. 1427-1448, 2019.

[19] B. A. Poulsen and D. P. Adhikary, "A numerical study of the scale effect in coal strength," International Journal of Rock Mechanics and Mining Sciences, vol. 63, pp. 62-71, 2013.

[20] D. O. Potyondy, "The bonded-particle model as a tool for rock mechanics research and application: current trends and future directions," Geosystem Engineering, vol. 18, no. 1, pp. 1-28, 2014.

[21] C. D. Martin, "The strength of massive Lac du Bonnet granite around underground openings," Ph. D. thesis, University of Manitoba, Winnipeg, Canada, 1993.

[22] S. Aziznejad, "Characterization of Impact-Induced Damage of Jointed Rock Masses," Ph. D. thesis, University of Toronto, Toronto, Canada, 2015. 